\title{
Modeling of Woodworkers' Exposure to Occupational Noises by Integrating Frequency Spectra Generated by Power Tools: A Pilot Study
}

\author{
Yu-Ping Zheng ${ }^{1}$, Yow-Jer Juang ${ }^{2}(\mathbb{D})$ and Lih-Ming Yiin ${ }^{1, *(\mathbb{D})}$ \\ 1 Department of Public Health, Tzu Chi University, 701, Sec. 3, Zhongyang Road, Hualien City 970374, \\ Taiwan; 106324117@gms.tcu.edu.tw \\ 2 Department of Occupational Safety and Health, Chang Jung Christian University, 1, Changda Rd., \\ Gueiren District, Tainan City 711301, Taiwan; juang1007@mail.cjcu.edu.tw \\ * Correspondence: lmyiin@mail.tcu.edu.tw; Tel.: +886-3-856-5301 (ext. 2273)
}

Received: 14 August 2020; Accepted: 14 September 2020; Published: 16 September 2020

\begin{abstract}
Woodwork is one of the occupations with high levels of noises. This pilot study attempted to simulate woodworkers' occupational noise exposure by integrating frequency spectra measured from individual power tools with the respective time of tool use. Five volunteering woodworkers participated in the study, and each wore a noise dosimeter with $1 / 1$ octave-band analysis during the work for exposure assessment. The information of use of tools and time of tool use was recorded by an on-site technician. Frequency spectra of common power tools, including circular saw, electric curve saw, orbit sander, router trimmer, drill machine, pillar drill machine, nail gun, and air compressor, were also individually measured by the dosimeter. Monte Carlo simulation was used to simulate the distances between tools and workers, which were used to determine noise levels in the modeling. The personal measurements of noise exposure were around $80 \mathrm{dBA}$ with peaks locating between 1 and $4 \mathrm{kHz}$ and were fairly matched by the simulated results. This pilot modeling is seemingly feasible and promising, and noise exposure could be assessed by multiple times of tool use with known noise characteristics of the tools. The convenient dose estimates could be useful for the hearing protection of woodworkers.
\end{abstract}

Keywords: exposure assessment; frequency spectrum; noise; simulation; woodwork

\section{Introduction}

Occupational noise is considered the major cause of noise-induced hearing loss (NIHL), which is sensorineural, usually bilateral, and irreversible with an early sign of "notching" at the high frequencies of 3,4 , or $6 \mathrm{kHz}$ of the spectrum [1,2]. It was estimated that $16 \%$ of hearing loss in adults worldwide (over 4 million disability-adjusted life years) was attributed to occupational noise in 2000, with larger proportions in developing countries or regions [3]. To protect workers from hearing impairment or loss, the International Labor Organization (ILO) recommended a warning and a dangerous limits of noise levels of 85 and 90 decibels measured on the A scale (dBA) for time-weighted average (TWA) over an $8 \mathrm{~h}$ work shift, respectively [4], and the limits were adopted to be permissible exposure levels (PELs) in the regulations by many countries. Although efforts to minimize the incidence of NIHL have been made in countries around the world, the global burden of NIHL is a significant health issue. According to a recent document of the World Health Organization (WHO), the global improvements on NIHL after the year 2000 were limited as a whole; there were even $27 \%$ of countries in the Americas that lacked legislation regarding PELs for occupational noise [5].

NIHL continues to be a prevalent health issue across a variety of industries, among which woodwork is of concern because of exposure to occupational noise at high levels [6-11]. An Indian 
survey showed that $28 \%$ of sawmill workers suffered NIHL [7]; a Nepalese cross-sectional study indicated that $31 \%$ of carpenters and $44 \%$ of sawyers met criteria for NIHL, and the noise levels ranged from 71.2 to $93.9 \mathrm{dBA}$ [11]. A study conducted in small-scale industries of Iran also demonstrated carpentry as one of working environments where the average noise levels were around $85 \mathrm{dBA}$ [8]. Woodwork usually requires use of a number of power tools for sawing, sanding, drilling, and other tasks, which could generate noises at different levels that induced NIHL. Besides personal protective equipment, monitoring of working environments is an effective but not practical approach for assessing noise exposure, because of the inconvenience of wearing personal sampling gear during the $8 \mathrm{~h}$ work. If there was an alternative that is easier and more practical than personal noise measurement, performing an assessment of noise exposure could be implemented more smoothly.

This pilot study attempted to validate an alternative to personal measurement of occupational noise by finding out frequently used woodwork tools, assessing doses and frequency spectra of individual power tools, and integrating noise data generated by individual tools with time periods of tool use. The simulated $8 \mathrm{~h}$ TWA noise exposures and frequency spectra by the alternative method matching on-site measurements suggests that noise exposure could be calculated with multiple times of tool use and known noise characteristics of the individual tools. Thus, recording use and operating time of each power tool during the $8 \mathrm{~h}$ work could estimate the TWA noise exposure for woodworkers. We expect this alternative method to bring convenience to noise exposure assessment and to facilitate prevention control of occupational noise for woodworkers.

\section{Materials and Methods}

\subsection{Simulation Modeling}

Because the concept of this pilot study was to simulate personal monitoring of occupational noise for woodworkers, we simplified the modeling settings to be one independent person working in presumably open space. Under such a circumstance, the major sources of noises that the worker was exposed to came from operating the power tools nearby. Should the one-person working scenario not be met, distancing from co-workers to lower the possible interference was acceptable. The distances between a woodworker and the power tools would significantly determine the sound levels of exposed noises, which went down with increasing distances. A new sound level could be calculated using the following formula:

$$
L_{1}-L_{2}=20 \log \frac{r_{2}}{r_{1}}
$$

where $L_{1}$ is the original sound level $(\mathrm{dB})$ at a distance of $r_{1}(\mathrm{~cm})$ from the sound source, and $L_{2}$ is the new sound level $(\mathrm{dB})$ at a new distance of $r_{2}(\mathrm{~cm})$. We could utilize this equation to convert acoustic data of operating power tools to that at different distances in the circumstances that workers might encounter in the modeling. To integrate the equivalent continuous noise level $\left(L_{e q}\right)$ from noise levels of various power tools, the following formula could be applied:

$$
L_{e q}=10 \log \left(p_{1} \times 10^{L_{1} / 10}+p_{2} \times 10^{L_{2} / 10}+\cdots+p_{n} \times 10^{L_{n} / 10}\right)
$$

where $L_{1}, L_{2}, \ldots L_{n}$ are noise levels of power tools after adjustment for distances, and $p_{1}, p_{2}, \ldots p_{\mathrm{n}}$ are time proportions of tool use. A-weighted $L_{e q}\left(\mathrm{LA}_{\mathrm{eq}}\right)$ was finalized and compared with the on-site personal measurement ( $\mathrm{LA}_{\mathrm{eq}}$ equal to TWA on the $3 \mathrm{~dB}$ rule) for each woodworker.

Monte Carlo simulation was applied as probabilistic modeling in the study. We used Oracle ${ }^{\circledR}$ Crystal Ball (Fusion Edition, Release 11.1.2.3.000), an add-on software to Microsoft ${ }^{\circledR}$ Excel 2010, to perform the simulation. The key variable in the simulation was the distance between the power tools and woodworkers' ears; we followed the workers' habits of tool use, and set up the distance variables as distributions for handheld tools and large-size machines (Figure 1). During the simulation, distances of tools were randomly selected following the given variable distributions to compute an

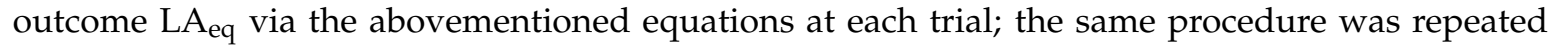


a million times to derive a cumulative result for $\mathrm{LA}_{\mathrm{eq}}$, a distribution with full simulated statistical information (e.g., mean, median, standard deviation).

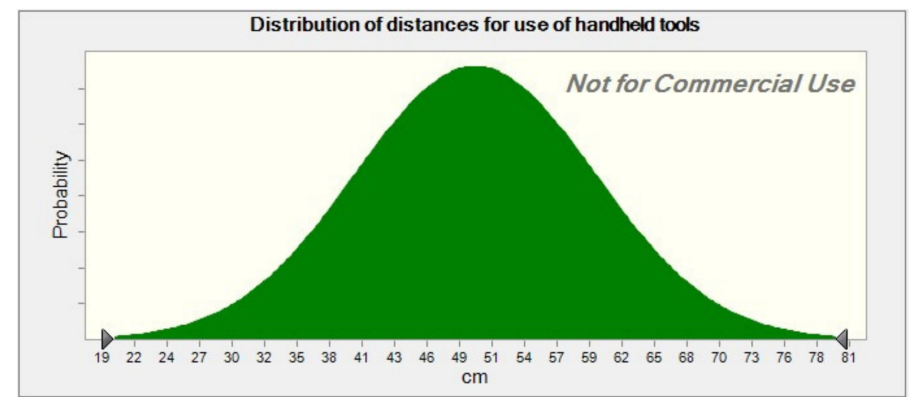

(a)

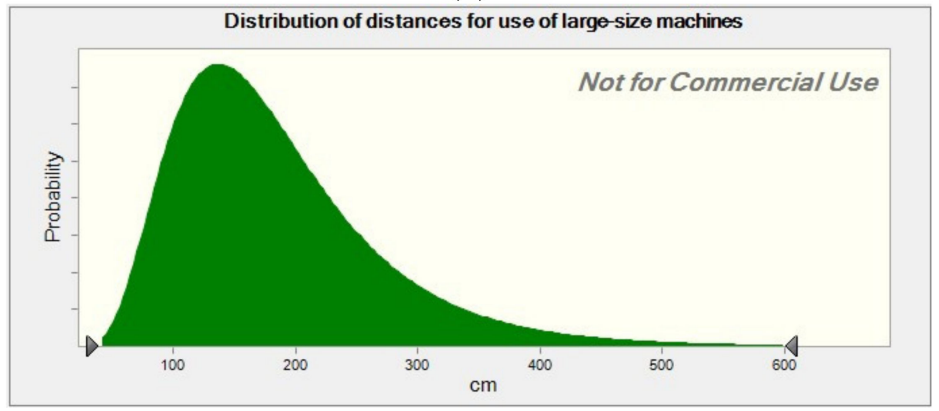

(b)

Figure 1. (a) Distance setting for curve saw, orbit sander, router trimmer, drill machine, and nail gun;

(b) Distance setting for circular saw, pillar drill machine, and air compressor.

\subsection{Personal Measurement}

We recruited five woodworkers, who volunteered to wear a noise dosimeter (SV 102 Dual Channel Noise Dosimeter, Svantek, Warsaw, Poland) during their daily work ( $\sim 8 \mathrm{~h})$. The Class 2 noise dosimeter, equipped with two ceramic microphones (SV 25D) that could be installed near both ears of the workers, simultaneously analyzed $1 / 1$ octave $(31.5$ to $8000 \mathrm{~Hz})$ and recorded audio events. A-weighting was used for measurement, and the threshold level and exchange rate were set at zero $\mathrm{dB}$ and $3 \mathrm{~dB}$, respectively; the slow time constant was selected to record sound levels at one-second intervals. Prior to every measurement, the dosimeter was calibrated for $94 \mathrm{~dB}$ at $1000 \mathrm{~Hz}$ using a sound-level calibrator (TES-1356, TES Electric Electronic Corp., Taipei, Taiwan). A field technician was on site to record information of use of power tools and the respective operating time periods, which were later used in the model of simulating occupational noise exposure. The informed consent and study protocols were in compliance with relevant laws and institutional guidelines and were approved by the Research Ethics Committee of Tzu Chi Hospital/University (IRB108-64-B, 16 April 2019).

\subsection{Power Tool Measurement}

The commonly used power tools by the five woodworkers were circular saw, electric curve saw, orbit sander, router trimmer, drill machine, pillar drill machine, nail gun, and air compressor. We used the same dosimeter to record frequency spectra ( $1 / 1$ octave) of the power tools in stable operation for one minute. Handheld tools, such as electric curve saw (TJ8517, Talon Tough Tools, Germiston, South Africa), orbit sander (Prima 5", Gen Power Pneumatic Tools Co., Taoyuan, Taiwan), router trimmer (TM-6, Metabo ${ }^{\circledR}$, Shanghai, China), drill machine (BE10, Metabo ${ }^{\circledR}$, Shanghai, China), and nail gun (422J, brand unknown, Taiwan), were kept $15 \mathrm{~cm}$ away for measurement, whereas large-size machines, including circular saw (GC1950R, Rexon ${ }^{\circledR}$, Taichung, Taiwan), pillar drill machine (ADT-500, KTL, New Taipei, Taiwan) and air compressor (Two Star CT-15A1, Chyi Tsuen Co., Taichung, Taiwan), were measured at a distance of $100 \mathrm{~cm}$. Background noises (e.g., music playing, noise generated from 
other workers' tasks) were also measured for use in the modeling, and the levels were relatively low $(<75 \mathrm{dBA})$ compared to those generated by most power tools ( $>80 \mathrm{dBA})$.

\section{Results}

The information of time of tool use for each woodworker is given in Table 1. Circular saw appeared to be the major tool to use for woodwork, and nail gun and air compressor were used by all workers. Time of tool use for these five cases was approximately $15-27 \%$ in proportion, and the remaining time was full of tasks of gluing, measuring, and material preparing. Unlike other tools that gave continuous noises, the nail gun generated a train of impulsive noises, which made the measurement of cumulative time of use difficult. For example, 18 min were roughly estimated for Subject 3, who actually used a nail gun all afternoon.

Table 1. Information of time of tool use for woodworkers.

\begin{tabular}{cccccc}
\hline \multirow{2}{*}{ Power Tool } & \multicolumn{5}{c}{ Time of Use (Min) } \\
\cline { 2 - 6 } & Subject 1 & Subject 2 & Subject 3 & Subject 4 & Subject 5 \\
\hline Circular saw & 20.00 & 58.00 & 48.00 & 57.00 & 44.25 \\
Curve saw & 4.00 & - & - & - & - \\
Orbit sander & - & 2.00 & 4.00 & 8.00 & 3.50 \\
Router trimmer & - & 7.00 & 14.00 & - & 9.50 \\
Drill machine & - & - & 11.25 & 25.50 & 10.00 \\
Pillar drill machine & - & - & - & 6.00 & 1.50 \\
Nail gun & 3.00 & 12.75 & 18.00 & 13.50 & 1.25 \\
Air compressor & 3.00 & 21.00 & 6.00 & 6.00 & 14.50 \\
No use (background) & 182 & 343 & 370 & 316 & 405 \\
\hline Total worktime & 212 & 443.75 & 471.25 & 432 & 489.5 \\
\hline
\end{tabular}

Frequency spectra of individual tools were measured for simulation modeling (Table 2). Generally speaking, the peaks of noises generated by handheld tools occurred between 1 and $4 \mathrm{kHz}$, except that generated by nail gun, peaking at higher frequencies (i.e., 4, $8 \mathrm{kHz}$ ). Large-size machines generated relatively low levels of noises with the peaks at $500 \mathrm{~Hz}$, except the circular saw that had the peak at $8 \mathrm{kHz}$. LA $\mathrm{eq} \mathrm{s}$ derived from personal measuring and simulation modeling, where median values of distances (i.e., $50 \mathrm{~cm}$ for handheld tools, $165 \mathrm{~cm}$ for large-size machines) were used in Equation (1) for conversion, are shown in Figure 2. It appeared that all five woodworkers were exposed to noise levels peaking between 1 and $4 \mathrm{kHz}$, and $\mathrm{LA}_{\mathrm{eq}} \mathrm{S}$ were around $80 \mathrm{dBA}$ with that for the right ear being slightly higher than the other (0.2 0.4 dBA). Although the simulated $\mathrm{LA}_{\mathrm{eq}} \mathrm{s}$ fairly matched that from the personal measuring, there were certain differences between both, with an underestimated value for Subject 1 and overestimated ones for the others. The estimated levels at 4 and $8 \mathrm{kHz}$ for Subjects 3 and 4 were apparently higher than that of on-site measurements, suggesting that the biases could be caused by tools that generated high noise levels at those frequencies.

Table 2. Frequency spectra (1/1 octave) measured from power tools in operation.

\begin{tabular}{ccccccccc}
\hline & \multicolumn{4}{c}{ Handheld Tool (dB) ${ }^{\mathbf{a}}$} & \multicolumn{3}{c}{ Large-size Machine (dB) $^{\mathbf{b}}$} \\
\hline $\begin{array}{c}\text { Frequency } \\
\mathbf{( H z )}\end{array}$ & $\begin{array}{c}\text { Curve } \\
\text { Saw }\end{array}$ & $\begin{array}{c}\text { Orbit } \\
\text { Sander }\end{array}$ & $\begin{array}{c}\text { Router } \\
\text { Trimmer }\end{array}$ & $\begin{array}{c}\text { Drill } \\
\text { Machine }\end{array}$ & $\begin{array}{c}\text { Nail } \\
\text { Gun }\end{array}$ & $\begin{array}{c}\text { Circular } \\
\text { Saw }\end{array}$ & $\begin{array}{c}\text { Pillar Drill } \\
\text { Machine }\end{array}$ & $\begin{array}{c}\text { Air } \\
\text { Compressor }\end{array}$ \\
\hline 31.5 & 55.3 & 51.7 & 28.0 & 41.2 & 41.7 & 34.3 & 54.1 & 36.8 \\
63 & 71.2 & 67.7 & 46.7 & 66.3 & 53.6 & 64.9 & 60.9 & 57.0 \\
125 & 69.2 & 85.8 & 51.7 & 70.7 & 61.1 & 63.5 & 69.5 & 61.3 \\
250 & 77.3 & 81.4 & 61.9 & 73.3 & 75.4 & 70.1 & 75.8 & 70.3 \\
500 & 84.2 & 78.1 & 77.2 & 86.0 & 84.1 & 74.6 & 88.1 & 78.7 \\
$1 \mathrm{k}$ & 88.4 & 91.8 & 90.9 & 88.1 & 96.1 & 74.2 & 88.0 & 71.1 \\
$2 \mathrm{k}$ & 90.7 & 86.7 & 89.5 & 89.8 & 94.1 & 75.8 & 83.6 & 69.2 \\
$4 \mathrm{k}$ & 87.0 & 87.6 & 87.1 & 89.7 & 97.7 & 84.2 & 82.4 & 69.4 \\
$8 \mathrm{k}$ & 82.8 & 87.1 & 81.4 & 82.8 & 98.5 & 88.0 & 75.6 & 63.4 \\
\hline \multicolumn{3}{c}{ a Measured from a distance of 15 cm; ${ }^{\mathrm{b}}$ measured from $100 \mathrm{~cm}$ away. }
\end{tabular}



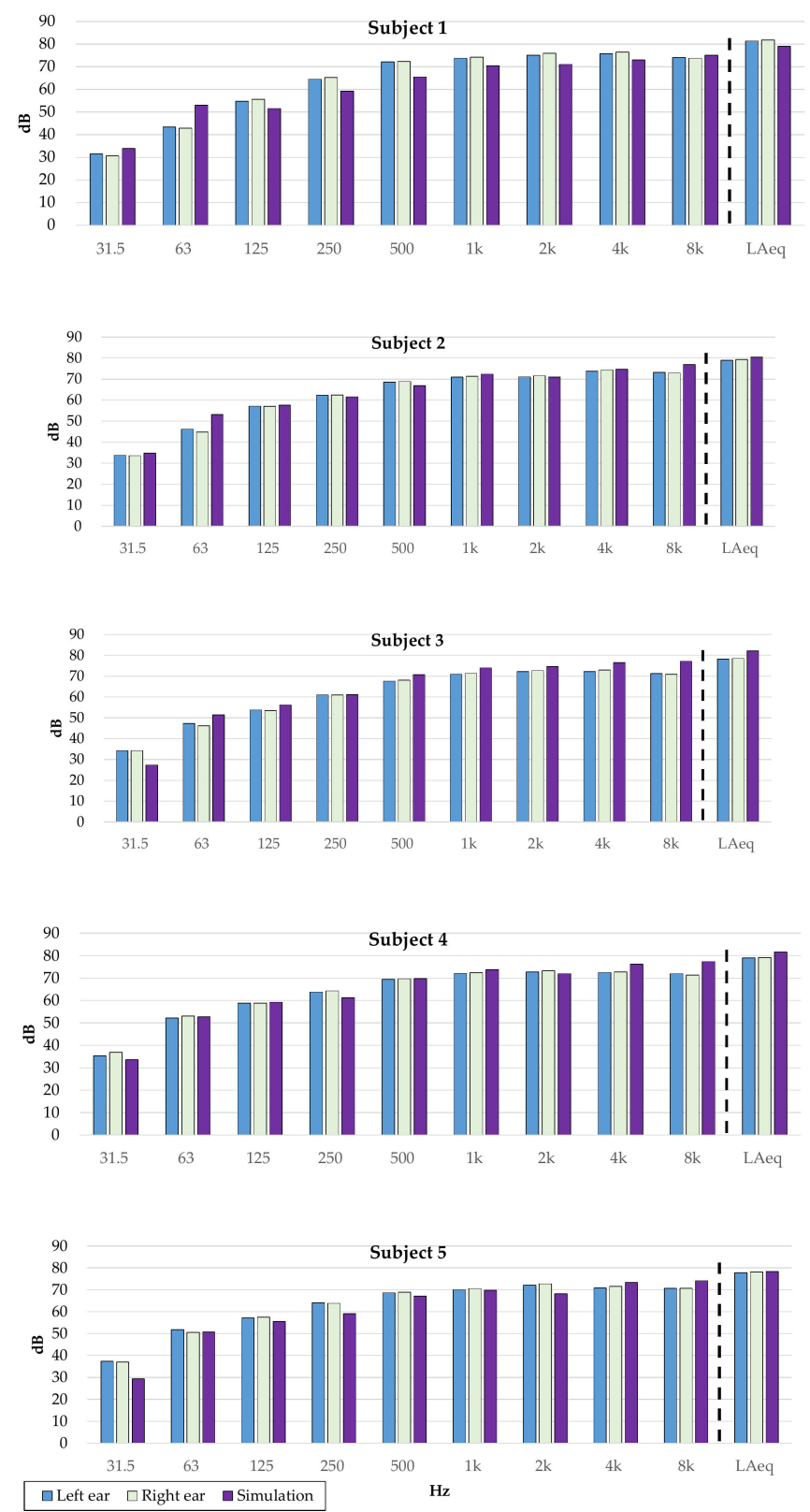

Figure 2. Frequency spectra and equivalent continuous noise levels $\left(\mathrm{LA}_{\mathrm{eq}} \mathrm{s}\right)$ of personal measurements and simulation results.

The Monte Carlo simulation data of variable distances from power tools are given in Figure 3. The distributions of simulated $\mathrm{LA}_{\mathrm{eq}} \mathrm{s}$ indicated that noise exposures could vary with distances between power tools and the subject workers as time of tool use was fixed. For example, noise exposure for Subject 2 could have more than $70 \%$ chances to be under the PEL of $85 \mathrm{dBA}$ but might be over with approximately $17 \%$ chances. The simulated distributions containing the real monitoring results for Subjects 1, 2, and 5 were in support of this alternative method for noise exposure assessment; however, the simulation results for the other two subjects did not come with good matches, indicating significant biases occurring in the two simulation events. This finding could be related to the overestimated levels at 4 and $8 \mathrm{kHz}$ for Subjects 3 and 4 , as stated in the previous paragraph. 

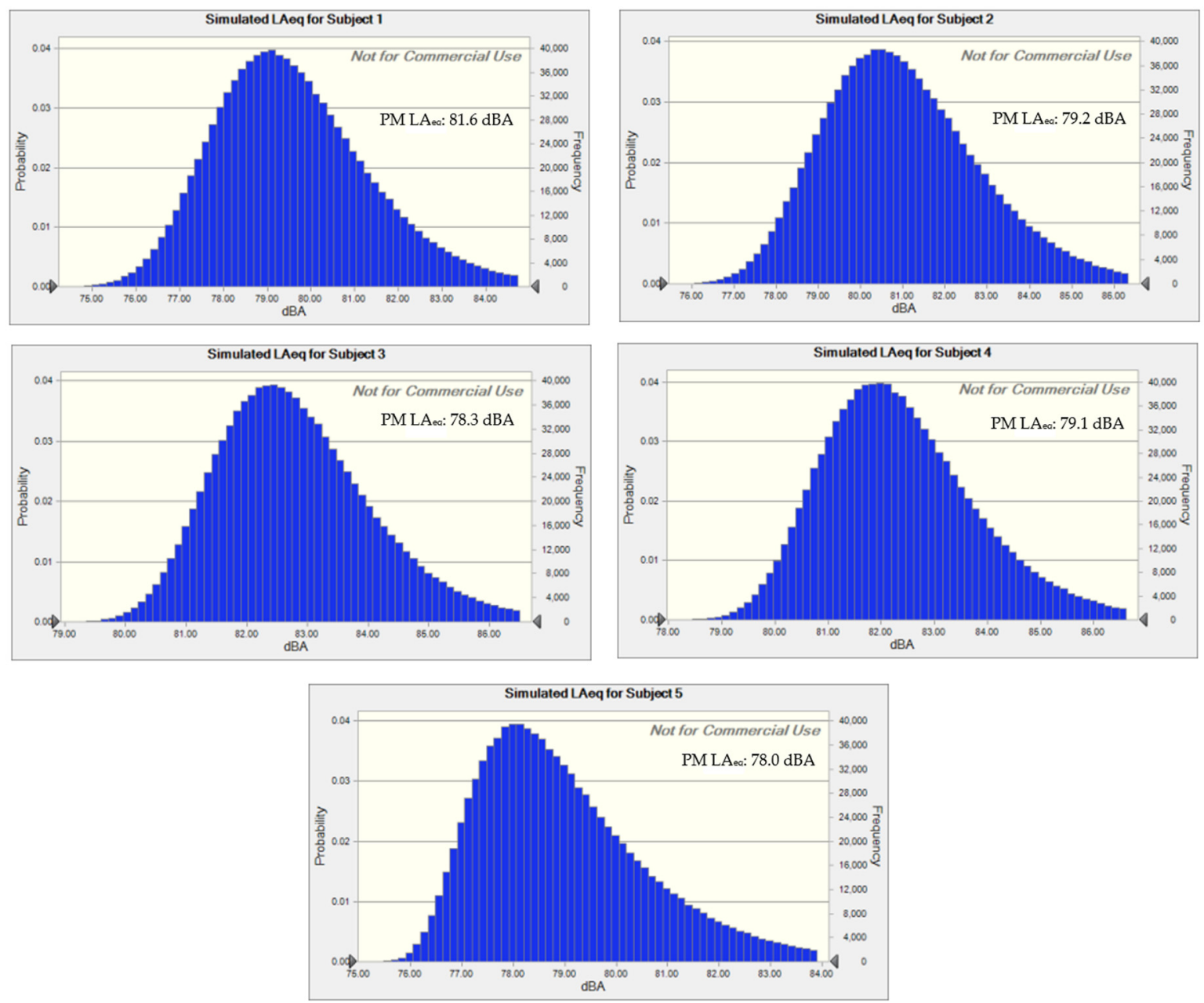

Figure 3. Monte Carlo simulation of $\mathrm{LA}_{\mathrm{eq}} \mathrm{s}$ for woodworkers (PM denotes personal measurement).

\section{Discussion}

A number of studies have shown that woodwork is one of occupations that could induce NIHL [6-11], and exposure to the occupational noises must be the major cause. This study showed that most of the commonly used tools (e.g., circular saw, drill machine) generated high noise levels peaking at $1-4 \mathrm{kHz}$, which corresponded to the audiometric "notching" at 3, 4, or $6 \mathrm{kHz}$, one of the early signs of NIHL [1,2]. From the personal monitoring, we also observed that noise exposure for the right ear was slightly higher than that for the left, suggesting that all five workers could be right-handed and accustomed to handling tasks on the right-hand side (Figure 2). Although the difference might be minimal, it could result in more severe hearing loss of the right ear in the long run. Future studies need to be warranted for investigating this issue.

The gap between the personal measurements and simulation results was likely due to several factors, one of which was the size of working environment. We obtained an underestimated result of simulation for Subject 1, who was working in a relatively small and closed room (roughly $3.5 \mathrm{~m} \times 4.5 \mathrm{~m}$ ), compared to those for the other four that were in open spaces with sizes of at least $6 \mathrm{~m} \times 9 \mathrm{~m}$. The situation was somewhat against the assumption of noises radiating in a free field, and echoes of the noises could have occurred during the working hours to enhance the $\mathrm{dB}$ levels. Reverberation time was confirmed to impact noise exposure in a previous study [12], and should be considered in future modeling work. As for the overestimated results, the distances of tools from the workers must have had an impact; the longer the distance was from the workers, the lower the noises they were exposed to. As the simulation was conducted as closely as possible to the real situations, certain occasions with larger distances appeared to be inevitable, especially while using large-size machines (e.g., circular saw). 
It was quite common that woodworkers left the power of the circular saw on while walking away for other tasks.

The simulation modeling seemed good to mimic personal monitoring data for cases with little use of nail gun (e.g., Subject 5), but not for those with heavy use. Subjects 3 and 4, who used nail guns quite a long time (18.00 and $13.50 \mathrm{~min}$, respectively), were actually exposed to noise levels much lower than simulated ( $79 \mathrm{dBA}$ vs. $82 \mathrm{dBA}$ ). The exceeding dB levels at 4 and $8 \mathrm{kHz}$ of the simulated results for Subjects 3 and 4 were probably attributed to nail gun use, which happened to generate the highest $\mathrm{dB}$ levels at 4 and $8 \mathrm{kHz}$ (Table 2). The bias could have resulted from overestimating the use of a nail gun, and we probably need a more sophisticated approach to deal with the use of a nail gun in the simulation modeling, considering the characteristics of impulsive noises.

Other than the nail gun issue, there were limitations in the study. Firstly, the sampling of frequency spectra of noises from power tools was limited to measurements from single tools. There must have been differences between tools of the same kind, which could cause simulation biases; moreover, the conditions of tools (i.e., new or old) would influence the noise generation. Fortunately, those differences appeared to be minimal, and the simulated $\mathrm{LA}_{\mathrm{eq}} \mathrm{s}$ and frequency spectra were close to those of the real measurements. Secondly, different materials might have resulted in different noise levels and frequencies; for example, working on metals usually generates high levels of noises at higher frequencies than does working on wood or stone [13]. As for working on wood of various kinds, the noise levels could be different but within a small range, according to our field testing. Thirdly, for simplicity of the modeling, we did not consider other sources of noises (e.g., noise generated by coworkers) and treated them as part of background noise in the modeling. The background noise in the five working environments varied from 50 to $75 \mathrm{dBA}$; compared to the noises generated by operating power tools ( $>80 \mathrm{dBA})$, the background noise at low or high levels could only contribute a shift of $1.5 \mathrm{dBA}$ or less to the net noise doses; thus, the modeling focusing on a single major source appeared to work. Finally, the function of the dosimeter was limited to $1 / 1$ octave measuring, which derived less delicate results than $1 / 3$ octave measuring. We are not sure whether using $1 / 3$ octave measurements could enhance the accuracy of simulation, but it is definitely a good attempt in future testing.

\section{Conclusions}

This piloting simulation modeling of woodworkers' noise exposure matching doses and frequency spectra of the real personal measurements appears to be feasible; it could estimate the noise exposure for woodworkers with multiple times of tool use and known noise information of power tools. Such dose estimates could be useful for hearing protection strategies, which should be practiced prior to work. The modeling is not perfect and definitely needs improving, particularly in assessing impulsive noises generated by certain tools (e.g., nail gun). An improved model in the future for assessing occupational noise exposure is expected.

Author Contributions: Conceptualization, Y.-P.Z. and L.-M.Y.; methodology, Y.-P.Z. and Y.-J.J.; software, Y.-P.Z. and Y.-J.J.; validation, Y.-P.Z. and L.-M.Y.; formal analysis, Y.-P.Z.; investigation, L.-M.Y.; resources, Y.-J.J.; data curation, Y.-P.Z.; writing—original draft preparation, Y.-P.Z.; writing—review and editing, L.-M.Y.; visualization, L.-M.Y.; supervision, L.-M.Y.; project administration, L.-M.Y. All authors have read and agreed to the published version of the manuscript.

Funding: This research received no external funding.

Acknowledgments: The authors would like to thank the five woodworkers who volunteered to participate in this study and the department of occupational medicine of Hualien Tzu Chi Hospital which assisted us by referring eligible subjects to this study.

Conflicts of Interest: The authors declare no conflict of interest.

\section{References}

1. Azizi, M.H. Occupational noise-induced hearing loss. Int. J. Occup. Environ. Med. 2010, 1, 116-123. [PubMed] 
2. Kirchner, D.B.; Evenson, E.; Dobie, R.A.; Rabinowitz, P.; Crawford, J.; Kopke, R.; Hudson, T.W. Occupational noise-induced hearing loss: ACOEM task force on occupational hearing loss. J. Occup. Environ. Med. 2012, 54, 106-108. [CrossRef] [PubMed]

3. Nelson, D.I.; Nelson, R.Y.; Concha-Barrientos, M.; Fingerhut, M. The global burden of occupational noise-induced hearing loss. Am. J. Ind. Med. 2005, 48, 446-458. [CrossRef] [PubMed]

4. Concha-Barrientos, M.; Campbell-Lendrum, D.; Steenland, K. Occupational Noise: Assessing the Burden of Disease from Work-Related Hearing Impairment at National and Local Levels; (WHO Environmental Burden of Disease Series, No. 9); World Health Organization: Geneva, Switzerland, 2004.

5. World Health Organization (WHO). Addressing the Rising Prevalence of Hearing Loss; World Health Organization: Geneva, Switzerland, 2018.

6. Noweir, M.H.; Bafail, A.O.; Jomoah, I.M. Noise pollution in metalwork and woodwork industries in the Kingdom of Saudi Arabia. Int. J. Occup. Saf. Ergon. 2014, 20, 661-670. [CrossRef] [PubMed]

7. Dhere, A.M.; Pawar, C.B.; Patil, D.A.; Pawar, J.A. Noise induced hearing loss (NIHL) in saw mill and printing press workers in Akluj Town of Solapur district. J. Environ. Sci. Eng. 2009, 51, 187-190. [PubMed]

8. Jabbari, K.; Nassiri, P.; Monazzam Esmaeelpour, M.R.; Azam, K.; Faridan, M.; Heidari, L. The relationship between occupational noise exposure and noise induced hearing loss (NIHL) in small-scale industries: A case study in the city of Damavand, Iran. Biotechnol. Health Sci. 2016, 3, 49-56. [CrossRef]

9. Bukuru, J.; Byiringiro, F.; Mukara, B.K.; Twagirumukiza, E.; Sayinzoga, C.; Ngoga, E.; Kagimbana, J.C. Prevalence of occupational noise induced hearing loss among wood and metal workers of Gakiriro, Kigali city. Rwanda Public Health Bull. 2019, 1, 20-25.

10. Yiin, L.M.; Young, C.H.; Chou, Y.T.; Wang, G.C.; Tseng, C.C.; Liu, H.W.; Hsieh, C.J. Assessment of noise exposure in decoration workers. Chin. J. Occup. Med. 2016, 23, 1-9. (In Chinese)

11. Robinson, T.; Whittaker, J.; Acharya, A.; Singh, D.; Smith, M. Prevalence of noise-induced hearing loss among woodworkers in Nepal: A pilot study. Int. J. Occup. Environ. Health 2015, 21, 14-22. [CrossRef] [PubMed]

12. Maffei, L.; Iannace, G.; Masullo, M. Noise exposure of physical education and music teachers. Noise Vib. Worldw. 2011, 10, 41-50.

13. Ottoni, A.O.; Barbosa-Branco, A.; Boger, M.E.; Garavelli, S.L. Study of the noise spectrum on high frequency thresholds in workers exposed to noise. Braz. J. Otorhinolaryngol. 2012, 78, 108-114. [CrossRef] [PubMed] 